\title{
$\mathrm{Ag}$ または K 添加 $\mathrm{p}$ 型 $\mathrm{PbTe}$ の熱電特性
}

\author{
野田泰稔* 折橋正樹什 西田勲夫** \\ *東北大学工学部材料物性学科 \\ **金属材料技術呼究所
}

J. Japan Inst. Metals, Vol. 61, No. 2 (1997), pp. 180-183

\section{Thermoelectric Properties of p-Type Lead Telluride Doped with Silver or Potassium}

\author{
Yasutoshi Noda*, Masaki Orihashi"† and A. Isao Nishida** \\ *Department of Materials Science, Faculty of Engineering, Tohoku University, Sendai 980-77 \\ **National Research Institute for Metals, Tsukuba 305
}

\begin{abstract}
Single crystals of $\mathrm{p}$-type $\mathrm{PbTe}$ were prepared by the Bridgman method, where either $\mathrm{Ag}_{2} \mathrm{Te}$ or $\mathrm{K}$ was doped as the source material of silver or potassium. The carrier concentration and Hall mobility were measured from 77 to $300 \mathrm{~K}$. The hole concentration was successfully controlled in the range from $2.0 \times 10^{24}$ to $9.0 \times 10^{24} \mathrm{~m}^{-3}$ by doping 100 to $700 \mathrm{~mol} \mathrm{ppm} \mathrm{Ag}_{2} \mathrm{Te}$, while the conduction type changed from p-to n-type in the region more than 1000 mol ppm $\mathrm{Ag}_{2} \mathrm{Te}$. In the case of $\mathrm{K}$-doping, the carrier concentration was controlled in the region $8.0 \times 10^{24}$ to $4.0 \times$ $10^{25} \mathrm{~m}^{-3}$ with 1000 to $20000 \mathrm{~mol}$ ppm K. The figures-of-merits $\mathrm{Z}$ of $\mathrm{PbTe}$ at $300 \mathrm{~K}$ were $8.0 \times 10^{-4} \mathrm{~K}^{-1}$ for p-type at a hole concentration of $1.0 \times 10^{25} \mathrm{~m}^{-3}(2000 \mathrm{~mol} \mathrm{ppm} \mathrm{K})$ and $1.38 \times 10^{-3} \mathrm{~K}^{-1}$ at $2.34 \times 10^{24} \mathrm{~m}^{-3}(200 \mathrm{~mol} \mathrm{ppm}$ $\mathrm{Ag}_{2} \mathrm{Te}$ ).

The diffusion lengths of dopant elements of $\mathrm{Ag}$ and $\mathrm{K}$ for $\mathrm{p}$-type and I for $\mathrm{n}$-type $\mathrm{PbTe}$ were estimated using the diffusion data. The result indicates that long-distance diffusion occurs in a short period in the case of $\mathrm{Ag}$ and $\mathrm{K}$, but not so much in the case of $\mathrm{I}$. Therefore, the PbTe carrier concentration functionally graded material (FGM) prepared by doping $\mathrm{Ag}$ or $\mathrm{K}$ might be soon changed into non-FGM due to the dopant diffusion, resulting in the decreased efficiency of thermoelectric energy conversion.
\end{abstract}

(Received October 3, 1996)

Keywords: lead telluride, p-type dopant, scattering mechanism, thermoelectricity, figure-of-merit,
diffusion

I . 緒言

$\mathrm{N}$ - V 化合物半導体 $\mathrm{PbTe}$ は中温域 $(400 \sim 800 \mathrm{~K})$ Kおける 最も高効率な爇電変換材料である，近年，熱電素子の高効率 化に愫子材料のキャりア濃度傾斜 (Functionally Graded Material, FGM) 化が有効であると考えられている(1).PbTe に㧍けるキャリア濃度 FGM に上る熱電素子作製のためには， $\mathrm{p}$ 型执よびn型の両伝導型に和いてキャリア濃度を低濃度か ら高濃度まで軏続的に制御することが必要である。これまで $\mathrm{n}$ 型 $\mathrm{PbTe}$ に新いてはキャリア濃度制御の可能性が検討さ れ, 著者らの研究加ら, $\mathrm{PbI}_{2}$ 添加により $5.0 \times 10^{23} \sim 5.0 \times$ $10^{25} \mathrm{~m}^{-3}$ の電子濃度制御が可能であり, $\mathrm{p}$ 型から $\mathrm{n}$ 型への 転換が起こり；また性能指数 $(Z)$ の最大值は $\mathrm{n}$ 型領域では $1.3 \times 10^{-3} \mathrm{~K}^{-1}$ をとり, $\mathrm{PbI}_{2}$ 添加量と爇電特性の関係が明 らかにされた(2)。一方， $\mathrm{p}$ 型不純物として Ag の他に Na， K などが知られている(3)(4).しかしながらこれらが添加された $\mathrm{PbTe}$ の熱電特性が十分に解明されているわけでない，本研 究では $\mathrm{Ag}$ 执よび $\mathrm{K}$ を添加した $\mathrm{p}$ 型 $\mathrm{PbTe}$ 単結晶を作製し,

†東北大学大学院(Graduate Student, Tohoku University)
添加の效果を熱電特性の測定によって明らかにすることを目 的とする.

\section{II. 実 験方 法}

$\mathrm{PbTe}$ 単結晶は成分元素の鉛特よびテルル(それぞれ公称 純度99.9999\%)を原料とし，これらの直接溶融の後, ブリ ッジマン法により作製した。ここで成長管は内径 $10 \mathrm{~mm}$, 長さ $120 \mathrm{~mm} て ゙ ， 一$ 端を円錐形に成形した透明石英管を用 いた. 封入は数回のアルゴン置換後, $10^{-1} \mathrm{~Pa}$ に括いて行っ た。また，成長管の破損して，試料が酸化するのを防止する ために，さらにこの成長管を内径 $17 \mathrm{~mm}$ の石英管に真空封 入した. 成分元素の配合組成比は $\mathrm{Pb}: \mathrm{Te}=1: 1$, 不純物と して $\mathrm{Ag}$ は $\mathrm{Ag}_{2} \mathrm{Te}$ の形で, $\mathrm{K}$ は金属 $\mathrm{K}$ の形で原料ととも炕 封入乙た. 結晶成長には縦型電気炉を用い，炉の最高温度は $1223 \mathrm{~K}$, 融点に打ける温度勾配は $1200 \mathrm{~K} / \mathrm{m}$, 降下速度は $4 \mathrm{~mm} / \mathrm{h}$ とた.

Hall 係数 $R_{\mathrm{H}}$ ，打よび電気伝導度 $\sigma$ は白金電極を用いて 4 端子(Van der Pauw)法により 77〜300 Kに特いて測定した. $\mathrm{Ag}$ または $\mathrm{K}$ は $\mathrm{PbTe}$ 中の $\mathrm{Pb}$ と置換しアクセプターとなる 
ほか格子間位置を占めドナーとなる可能性もあるので， Hall 係数からキャリア濃度の算出には正味のキャリア濃度 として $\left|N_{\mathrm{A}}-N_{\mathrm{D}}\right|=1 / e R_{\mathrm{H}}(\mathrm{e}:$ 素電荷) の関係式加ら, Hall 移 動度 $\mu_{\mathrm{H}}$ は $\mu_{\mathrm{H}}=R_{\mathrm{H}} \sigma$ から求めた。熱電能 $\alpha$ は室温において $5 \mathrm{~K}$ 以内の温度差で熱起電力と温度差の直線関係から決定し た.

\section{III. 結果および議論}

\section{1. 試料の熱電的性犋}

Fig. 1 に $\mathrm{Ag}_{2} \mathrm{Te}$ または $\mathrm{K}$ 添加量とキャりア濃度の関係を 示す(5). 図中の破線は，銀执よびカリウムが鉛格子位置を占 め1価にイオン化すると仮定した場合の関保を示す。 $\mathrm{Ag}_{2} \mathrm{Te}$ 100 700 mol ppm の範囲で，キャリア濃度の実測值 は計算値に近い値を取る。また，1000 mol ppm $\mathrm{Ag}_{2} \mathrm{Te}$ 付近 で $\mathrm{p}$ 型から $\mathrm{n}$ 型に変換する。この変換は銀の格子間原子ま

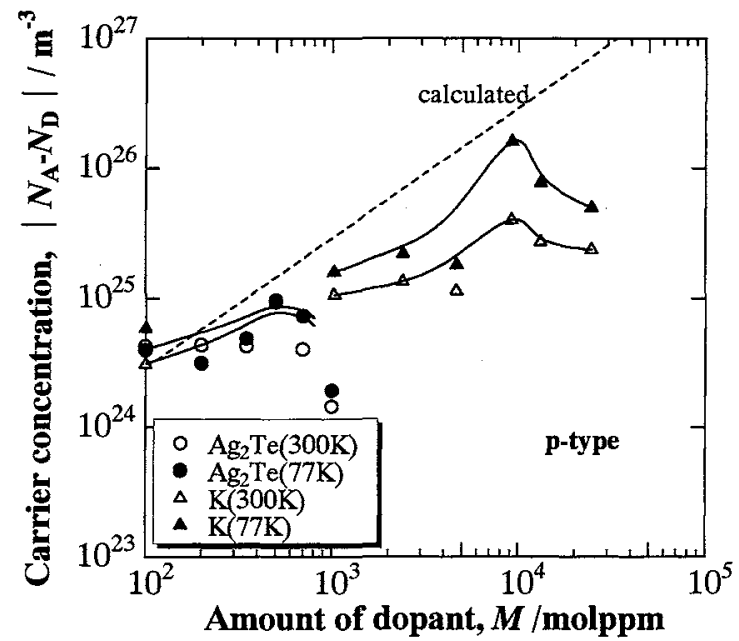

Fig. 1 Plots of carrier concentration versus amount of dopant in $\mathrm{Ag}_{2} \mathrm{Te}$ - or $\mathrm{K}$-doped p-type $\mathrm{PbTe}$.

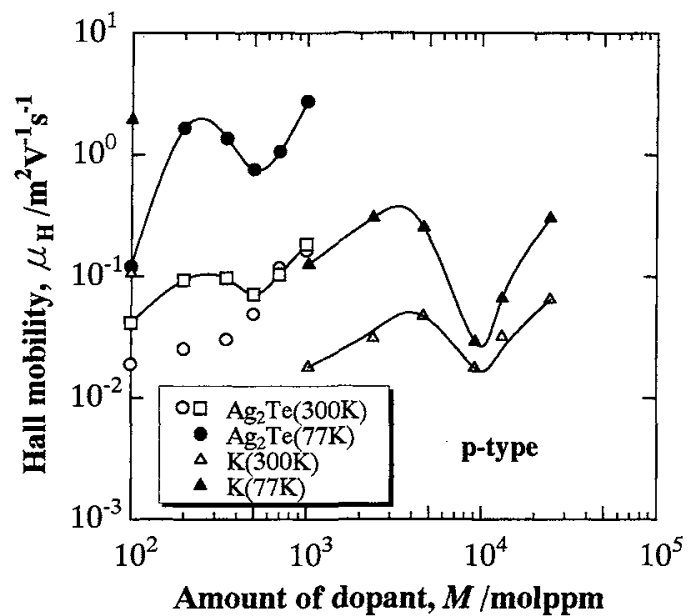

Fig. 2 Plots of Hall mobility versus amount of dopant in $\mathrm{Ag}_{2} \mathrm{Te}$ - or K-doped p-type $\mathrm{PbTe}$.
たは $\mathrm{n}$ 型析出物などに起因すると考穴られる(3). $\mathrm{Ag}_{2} \mathrm{Te}$ 添加 による $\mathrm{p}$ 型 $\mathrm{PbTe}$ 飞打忛るキャリア濃度の変化は $2 \sim 9 \times$ $10^{24} \mathrm{~m}^{-3}$ の狭い範团であった。キャリア濃度の $\mathrm{K}$ 添加量依 存性は $\mathrm{Ag}_{2} \mathrm{Te}$ 添加の昜合の延長上にあり， $\mathrm{Ag}$ 和よび $\mathrm{K} は$ $\mathrm{PbTe}$ 結晶格子内では，乙もに同様の分布と電子状態にある ことを示唆する．K 添加による最大キャリア濃度は $300 \mathrm{~K}$ に执いて約 $4 \times 10^{25} \mathrm{~m}^{-3}$ の值を取ることがわかる。李た $\mathrm{K}$

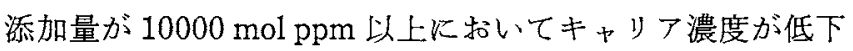
した.

Fig. 2 に Hall 移動度と不純物添加量の関係を示す．金属 $\mathrm{K}$ を添加した試料は $\mathrm{Ag}_{2} \mathrm{Te}$ を添加した試料に比べ低い值を 取る、これは原料の金属 $\mathrm{K}$ と結合していた酸素の影響によ るものと考えられる。従来 $\mathrm{p}$ 型PbTeに括けるキャリアの 移動度はn型の約 $1 / 2$ とされてさたが(6), 本研究に特いて 求められた $\mathrm{Ag}_{2} \mathrm{Te}$ 添加試料比ける $\mathrm{Hall}$ 移動度は, 上う素 添加 $\mathrm{n}$ 型材料に注济元敵する值をるつことから， $\mathrm{p}$ 打よび $\mathrm{n}$ 型 $\mathrm{PbTe}$ による高効率熱電変換素子の形成が可能となる(2).

不純物添加 $\mathrm{PbTe}$ に扣けるHall 移動度の温度依存性を $\mathrm{Ag}_{2} \mathrm{Te}$ 添加 $\mathrm{p}$ 型試料に対し Fig. 3 に，委た $\mathrm{K}$ 添加試料に ついて Fig. 4 に示す。図中の数字はそれぞれ $\mathrm{Ag}_{2} \mathrm{Te}$ 特よび 金属 $\mathrm{K}$ の添加量である.この図から温度の上昇とともに Hall 移動度が単調に減少することがわかる. 一般に温度 $T$ と移動度 $\mu$ の関係式は散乱因子 $r$ を用いて次式で表される。

$$
\mu \propto T^{-3 / 2+r}
$$

ここでノの值はキャりアの散乱機構に依存する．散乱機構は 一般に音響フォノン散乱が支配的な場合は $r=0.0$ であり， 不純物散乱が支配的である場合には $r=3.0$ である. $\mathrm{Ag}_{2} \mathrm{Te}$ 添加の場合，100〜350 mol ppm では散乱因子はいずれも $r=-0.5$ であり，500和よび $700 \mathrm{~mol} \mathrm{ppm}$ に打いて，rはそ れぞれー0.20 およびー0.17 と見積もられた．K添加の場合 1000 25000 mol ppm の範囲では添加量の増大に伴い $\boldsymbol{r は ~}$

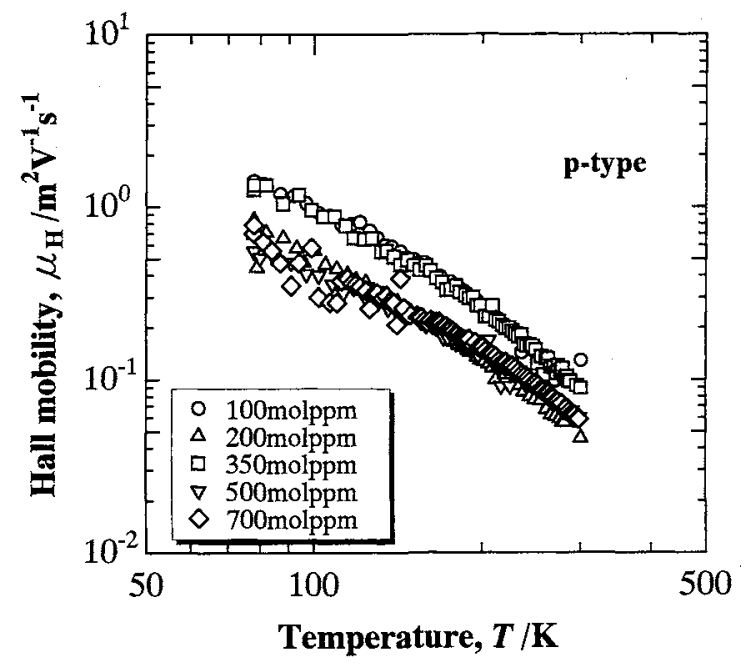

Fig. 3 Temperature dependence of Hall mobility in $\mathrm{Ag}_{2} \mathrm{Te}-$ doped p-type $\mathrm{PbTe}$ (the numbers indicate amount of $\mathrm{Ag}_{2} \mathrm{Te}$ in $\mathrm{mol} \mathrm{ppm}$ ). 


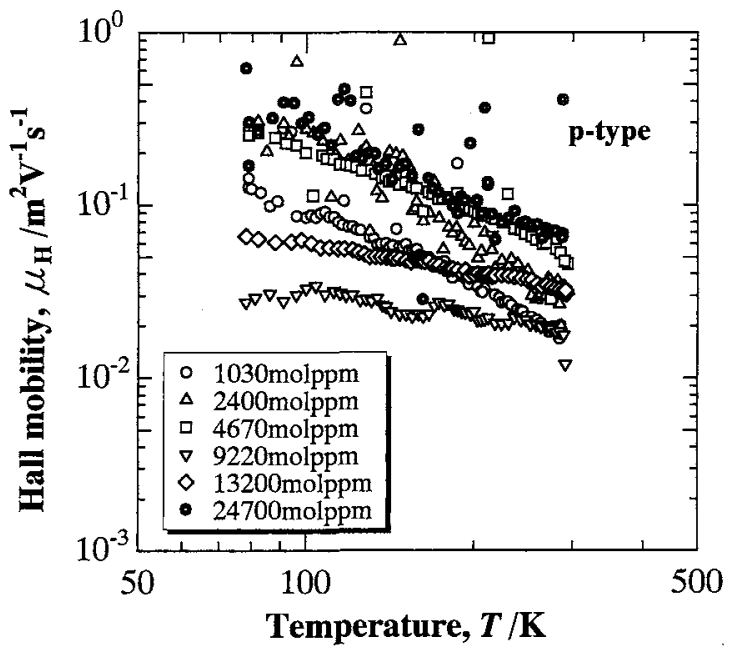

Fig. 4 Temperature dependence of Hall mobility in K-doped $\mathrm{p}$-type $\mathrm{PbTe}$ (the numbers indicate amount of $\mathrm{K}$ in mol ppm).

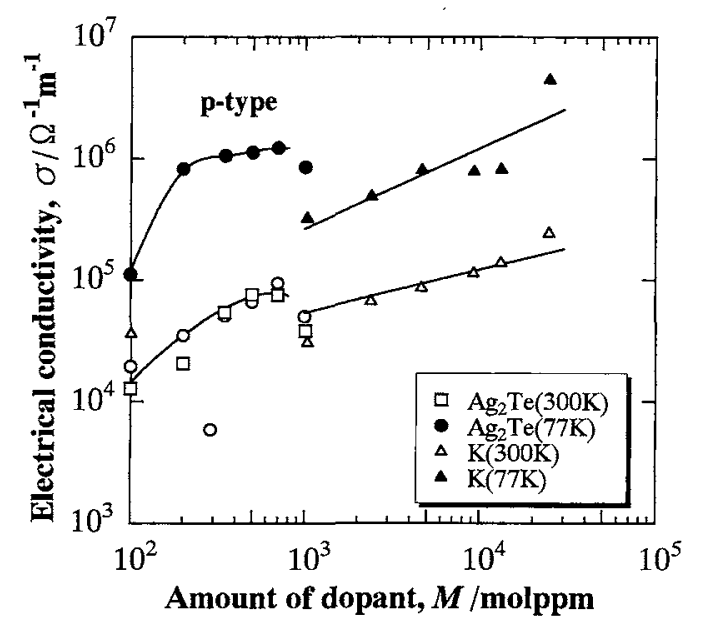

Fig. 5 Plots of electrical conductivity versus amount of dopant in $\mathrm{Ag}_{2} \mathrm{Te}$ - or $\mathrm{K}$-doped p-type $\mathrm{PbTe}$.

-0.17から+0.95 亿と増大する。この結果は, $\mathrm{Ag}$ 拈よび $\mathrm{K}$ 添加 $\mathrm{PbTe}$ では，主な散乱機構がフォノン散乱であり(7), 不純物添加量の増大に伴い不純物散乱の寄与が増大すること を示している。

Fig. 5 亿電気伝導度 $\sigma$ と不純物添加量の関係を示す. $\sigma$ は添加量が増加するにつれて増大することがわかる。しかし $\mathrm{K}$ 添加試料の值が $\mathrm{Ag}_{2} \mathrm{Te}$ 添加試料の電気伝導度の曲線の延 長上にないのは $\mathrm{K}$ 添加の際の酸素の混入による移動度の低 下のためと考えられる。

Fig. 6 亿室温に特ける熱電能 $\alpha$ と不純物添加量の関係を 示す。 $\alpha$ は不純物添加量が多くなるにつれて単調に減少する ことがわかる。

熱電性能指数 $Z$ は次式で表される。

$$
Z=\alpha^{2} \sigma / \kappa
$$

ここで，火は熱厷導率である. Fig. 7 亿 $\mathrm{Ag}_{2} \mathrm{Te}$ 添加和よび

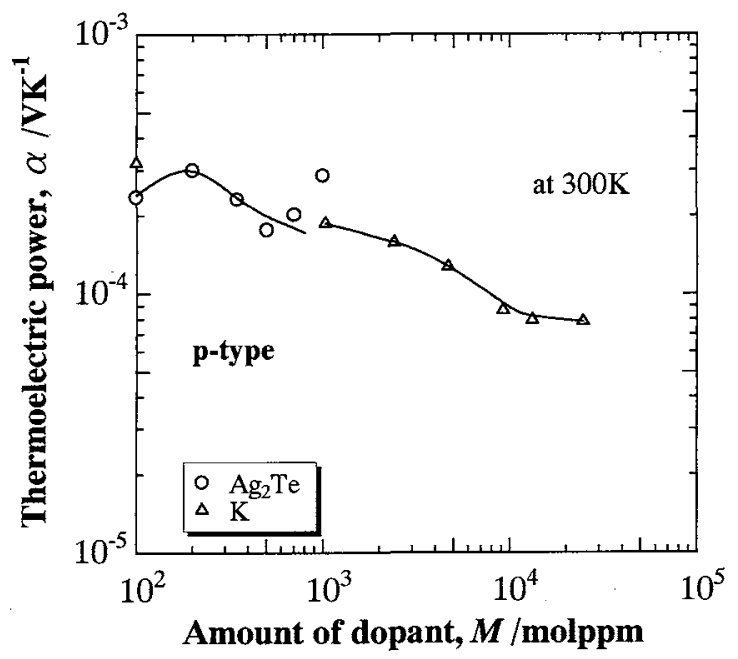

Fig. 6 Plots of thermoelectric power versus amount of dopant in $\mathrm{Ag}_{2} \mathrm{Te}$ - or $\mathrm{K}$-doped p-type PbTe.

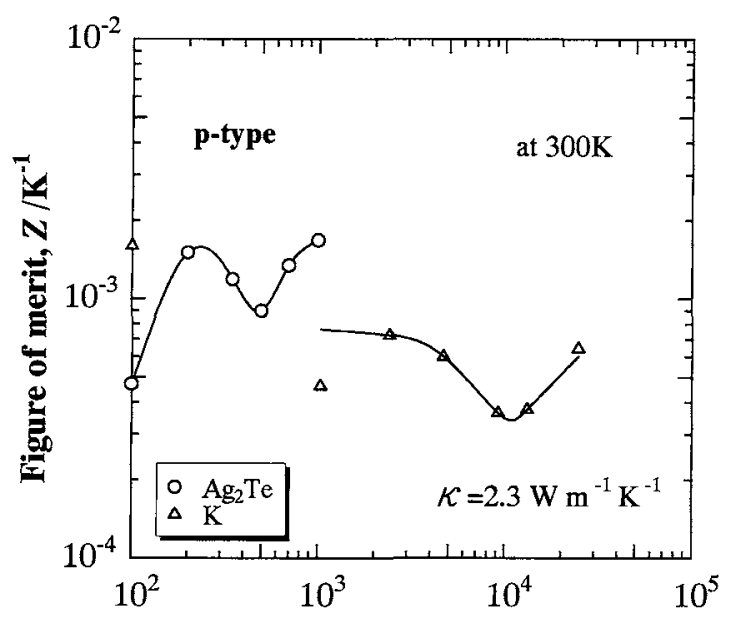

Amount of dopant, $M$ /molppm

Fig. 7 Plots of figure of merit versus amount of dopant in $\mathrm{Ag}_{2} \mathrm{Te}$ - or K-doped p-type PbTe.

$\mathrm{K}$ 添加試料に対して式(1)を用い $\alpha$ 括よび $\sigma$ の或測值と熱 云導率 $\kappa$ の文献値 $2.3 \mathrm{Wm}^{-1} \mathrm{~K}^{-1(8)}$ 加ら求めた性能指数 $Z$ を示す．ZU200〜 $500 \mathrm{~mol} \mathrm{ppm} \mathrm{Ag}$ 和よび 2000〜9000 mol ppm K の領域では添加量の増大とともに単調に減少す

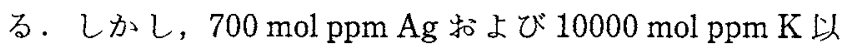
上で $Z$ は逆に増大寸る㑯向にある。これら多量添加領域の 挙動はこれら不純物元素が形成する欠陥の状態とる関連する と考光られ，今後さらに検討が必要である.

\section{2. $\mathrm{PbTe}$ 中の添加不純物の拡散}

不純物添加によりキャリア濃度 FGM を作製する際, それ らの安定性を検討することは極めて重要である。ここでは添 加不純物が拡散し, 所定のキャリア濃度傾斜 FGM が崩れて 非FGM 化するのに要する時間を見積もった。 Table 1 に 
Table 1 Diffusion data for $\mathrm{PbTe}$.

\begin{tabular}{l|l|l|l|l|l}
\hline Diffusant & $\begin{array}{c}D_{0} \\
\left(\mathrm{~m}^{2} / \mathrm{s}\right)\end{array}$ & $\begin{array}{c}\Delta E \\
(\mathrm{eV})\end{array}$ & $\begin{array}{c}\text { Temperature } \\
\text { range }(\mathrm{K})\end{array}$ & Mechanism & $\begin{array}{c}\text { Time for 1 mm } \\
\text { diffusion } \\
\text { (at 800 K) }\end{array}$ \\
\hline $\mathrm{K}^{*}$ & $1.7 \times 10^{-5}$ & 1.91 & $873-1123$ & vacancy & $1981 \mathrm{y}$ \\
$\mathrm{K}^{*}$ & $5.6 \times 10^{-10}$ & 0.4 & $673-1123$ & interstitial & $6.8 \mathrm{~d}$ \\
$\mathrm{Ag}^{* *}$ & $7.4 \times 10^{-8}$ & 0.35 & $673-1123$ & interstitial & $0.60 \mathrm{~h}$ \\
$\mathrm{I}^{* * *}$ & $1.6 \times 10^{-12}$ & 0.45 & $673-1123$ & - & $13 \mathrm{y}$ \\
\hline
\end{tabular}

*,** and ${ }^{* * *}$ from the data for $\mathrm{Na}, \mathrm{Ag}$ and $\mathrm{Cl}$ in $\mathrm{PbSe}^{(0)}$.

$\mathrm{PbTe}$ に括ける $\mathrm{p}$ 型不純物の $\mathrm{Ag}$ 执よび $\mathrm{K}, \mathrm{n}$ 型不純物の $\mathrm{I}$ に対する拡散係数 $D_{0}$ 括よびそれに関する諸定数 ${ }^{(9)}$ を示す。

表にはこれら払散係数を用い $800 \mathrm{~K}$ に执いて不純物原子が 距離 $1 \mathrm{~mm}$ だけ拡散するに要する時間を計算した結果を合 わせて示す，ただし各データは $\mathrm{PbSe}$ 中に括ける $\mathrm{Na}, \mathrm{Ag}, \mathrm{Cl}$ の桩散係数の值を用いた。ここで温度 $T \mathrm{~K}$ に挡ける桩散係 数 $D$ は式(3)で表される.

$$
D=D_{0} \exp (-\Delta E / k T)
$$

ここで $k$ はボルッマン定数 $\left(k=1.38 \times 10^{-23} \mathrm{JK}, 1 \mathrm{eV}=1.60\right.$

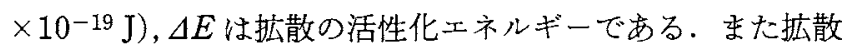
距離 $x$ と時間 $t$ との関保は式 $(4)$

$$
x=\sqrt{D t}
$$

を用いた。

熱電変換には10年間メンテナンスフリーの素子形成が望 なしいことを考虑すると，これらの結果より $\mathrm{n}$ 型不純物の Iについては，拡散速度が小さく長寿命の FGM が期待でき る. 一方， $\mathrm{p}$ 型不純物 $\mathrm{K}(\mathrm{Na})$ の拡散係数はその機構が格子 間原子による場合は，空格子点による場合に比べて非常に大 きい，Ag は同機構による場合は $\mathrm{K}(\mathrm{Na})$ よりもさらに大きい 值を取り，大きな拡散距離となる。熱電材料は多くの場合焼 結体により構成され，イオン半径の小さな $\mathrm{K}(\mathrm{Na}) や \mathrm{Ag} な$ どの不純物の桩散は格子間原子や久陷を経由して起こると考 えられることから，短期間の内に FGM から非FGM への变 化が起こり，効率の低下を引き起こす可能性がある。また $\mathrm{Ag}$ 添加 $\mathrm{PbTe}$ の電気的性質についてこれまで熱娃理による 複雑な挙動が報告されている(3). 搪散係数の計算により, $\mathrm{Ag}$ は掋散速度が極めて大きいことが知られたことから，こ のよらな挙動の原因は拡散比よる分布状態が複雑な変化によ ると考学られる。よって，今後はさらに他の $\mathrm{p}$ 型材料(例壳 ばTAGS 系や GeTe 系)の作製とFGM 化の研究が重要であ る.

\section{N. 結 論}

（1）ブリッジマン法により $\mathrm{Ag}_{2} \mathrm{Te}$ なは $\mathrm{K}$ 添加 $\mathrm{p}$ 型
$\mathrm{PbTe}$ 溶製材を作製した。 $\mathrm{Ag}_{2} \mathrm{Te}$ 添加に括いては 100〜700 mol ppm の添加で $2.0 \times 10^{24} \sim 9.0 \times 10^{24} \mathrm{~m}^{-3}$ の制御が可能 となり，1000 mol ppm 以上でn型に転換した． $\mathrm{K}$ 添加では 1000 25000 mol ppm な゙添加することにより FGMに必 要なキャリア濃度 $2.0 \times 10^{24} \sim 4.0 \times 10^{25} \mathrm{~m}^{-3}$ の制御が可能と なった。

（2）金属 Kを添加した試料の熱電特性の添加量依存性は $\mathrm{Ag}_{2} \mathrm{Te}$ 添加の場合のほぼ延長線上近くにあることが明らか となった.このことは $\mathrm{Ag}_{2} \mathrm{Te}$ 添加量が $700 \mathrm{~mol} \mathrm{ppm} \mathrm{以下の}$ 場合は，ほぼ $\mathrm{Pb}$ 空格子点に $\mathrm{Ag} か ゙$ 位置し，その添加量の範 囲での $\mathrm{Ag}$ 扎よび広範囲に添加した $\mathrm{K} は \mathrm{PbTe}$ 結晶格子内 では，とすに同様の分布と電子状態にあることを示唆する。

(3) K 添加を行った試料は低いHall 移動度を有し，原料 $\mathrm{K}$ と結合する酸素の影響の可能性が考㝋られる。また，そ の試料がかなり脆く、大型単結晶試料の作製が困難であっ た。

（4）拡散俰数をもとに $\mathrm{PbTe}$ 中の $\mathrm{I}, \mathrm{Ag}$ 执よび $\mathrm{K} の 800$

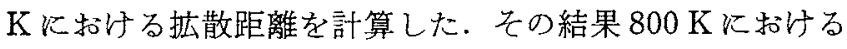
$\mathrm{n}$ 型不純物でめるI は应散距離が小さく，FGM 作製のため の添加不純物に適する。一方, p 型不純物 $\mathrm{Ag}, \mathrm{Na}$ 牤よび $\mathrm{K}$ は搪散距離が大きく, FGM から非 FGM への移行が起こり やすく安定な FGM 形成に適した不純物添加元素ではない。 それゆ光，他の中温域 $\mathrm{p}$ 型熱電材料(例觉ばTAGS 系や GeTe 系) の作製と FGM 化の研究が今後重要である。

\section{文献}

(1) M. Niino and L.-D. Chen: Proc. 12th Int. Conf. Thermoelectrics (XII-ICT), ed. by Matsuura, Yokohama, IEE Japan, (1993), 527.

(2) Y. Noda, M. Orihashi and I. A. Nishida: 熱電変換シンポジゥム '95 論文集 (1995), 40 ; 電気学会論文誌 A, 116-A (1996), 242.

(3) M. Battaglioli, V. Fano, G. Mignoni and Pergolari: Proc. 4th Int. Conf. on Thermoelectric Energy Conversion (ICTEC), Arligton, IEEE, (1982), 114

（4）上村欣一，西田勲夫：熱電半導体とその応用，日刊工業新聞 社, (1988), 179.

(5) Y. Noda, M. Orihashi and I. A. Nishida : 熱電変換シンポジウ 厶'96(TEC'96)論文集, (1996), 20.

(6) Yu. I. Rarich, B. A. Efimova and I. A. Smirmov: Semiconducting Lead Chalcogenides, Prenum Press, New York, (1970), 90, 354.

(7) R. S. Allgaier and W. W. Scanlon: Phys. Rev., 111(1958), 1029.

(8) Thermophysical Properties of Matter. vol. 1, Thermal Conductivity Metallic Elements and Alloys, ed. by Y. S. Touloakian, R. W. Powell, C. Y. Ho and P. G. Klements, IFI/PLENUM, New York, (1970), 1307

(9) R. Dalven: Infrared Phys., 9 (1969), 141. 